suggests a direct action on bone, as has been shown in tissue culture. ${ }^{5}$ The previous thyroidectomy and parathyroid removal, with the lack of response to calcitonin, indicate that the reduction in bone resorption could not have been mediated by a reduction in parathyroid hormone secretion or rise in endogenous calcitonin. It is unlikely that developing hypothyroidism played any major part in the action of hydrocortisone on bone resorption in this patient, since the response to hydrocortisone was rapid and the plasma half life of T4 is of the order of 6-7 days. Indeed, after the initial withdrawal of the thyroid supplements there was a steady increase in bone resorption until the administration of hydrocortisone.

1 Dent, C E, British Medical fournal, 1956, 1, 230.

2 Storey, E, Endocrinology, 1961, 68, 533.

3 Gallagher, J C, et al, Clinics in Endocrinology and Metabolism, 1973, 2, 355.

4 Nordin, B E C, Calcium, Phosphate and Magnesium Metabolism. Edinburgh, Churchill Livingstone, 1976.

5 Stern, P H, fournal of Pharmacology and Experimental Therapeutics, 1969, 168, 211.

(Accepted 17 November 1978)

MRC Mineral Metabolism Unit, The General Infirmary, Leeds LS1 3EX

P J HEYBURN, MB, MRCP, honorary registrar

$R M$ FRANCIS, $M B$, senior house officer

M PEACOCK, MB, FRCP, honorary consultant physician

\section{Hypoxic stillbirth due to entangled intrauterine catheter}

Uterine pressure is recorded, using polyvinyl intrauterine catheters, in many obstetric units practising active management of labour. It carries only a small risk to mother or fetus. ${ }^{1}$ There have been only sporadic reports of uterine perforation or disruption of fetal vessels. ${ }^{2-4}$ A case has been described of umbilical cord entanglement. We report a similar experience. ${ }^{5}$

\section{Case report}

The patient, a 31-year-old primigravida, had conceived after 10 years of voluntary infertility. She was admitted at 38 weeks' gestation for rest and observation because of pre-eclampsia. The results of tests for fetal welfare were satisfactory. Labour was induced at term by artificial rupture of the membranes and intravenous oxytocin. A fetal scalp electrode was applied and an intrauterine pressure catheter introduced to $15 \mathrm{~cm}$ by the standard technique. The fetal heart rate at that time was normal. Initial progress in labour was slow but acceptable. A lumbar epidural block provided analgesia After several hours of strong contractions variable decelerations of the fetal heart rate (FHR) were noted (figure) and the progress of labour was un-

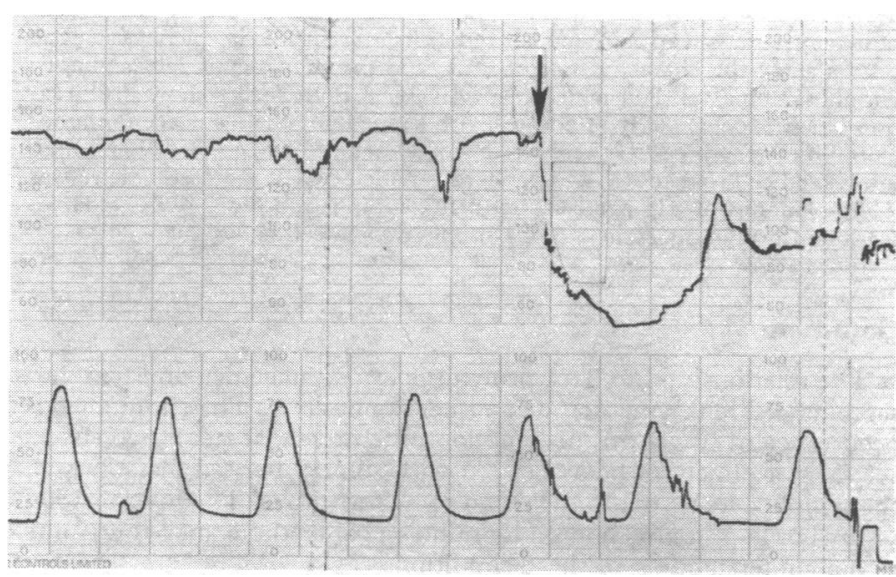

Recording showing variable decelerations of fetal heart rate due to compression of umbilical cord. Attempted removal of intrauterine catheter produced sharp (arrow) and sustained fall in rate. satisfactory. It was decided to perform lower-segment caesarean section. An attempt to remove the intrauterine catheter met with resistance and coincided with a sharp fall in the FHR, which recovered after several minutes. When the patient was anaesthetised a further attempt to withdraw the catheter was made but abandoned. A fresh stillborn infant weighing $3560 \mathrm{~g}$ was delivered. At operation the catheter was found to be acutely kinked and entangled in the umbilical cord, which was compressed.

\section{Comment}

Usually intrauterine pressure monitoring using a polyvinyl intrauterine catheter is safe. In our case we did not appreciate that the catheter was compressing the cord during labour, producing variable deceleration of the FHR. Trying to remove it led to intrauterine asphyxia and fetal death. If variable decelerations in FHR occur with an intrauterine catheter in situ umbilical cord compression by the catheter should be considered. When a gentle attempt to remove the catheter meets with resistance or produces further deceleration of the FHR further attempts to remove it should not be made.

1 Roux, J F, Newman, M R, and Goodlin, R C, CRC Critical Reviews in Bio-engineering, 1975, 2, 119.

2 Chan, W H, Paul, R H, and Toews, J, Obstetrics and Gynecology, 1973, 41, 7. ${ }^{3}$ Fernandez-Rocha, L, and Oullette, R, American fournal of Obstetrics and Gynecology, 125, 1976, 1153.

${ }^{4}$ Nuttall, I D, British Fournal of Obstetrics and Gynaecology, 1978, 85, 573.

5 Trudinger, B J, and Pryse-Davies, J, British fournal of Obstetrics and Gynaecology, 1978, 85, 567.

(Accepted 15 November 1978)

Department of Obstetrics and Gynaecology, Royal United Hospitals, Bath, Avon

DONALD G CAVE, MB, MRCOG, registrar

GORDON R SWINGLER, FRCSED, MRCOG, senior registrar

PETER G SKEW, MB, senior house officer

\section{Successful treatment of malignant testicular teratoma with brain metastases}

The outlook for some patients with metastatic testicular teratoma has improved considerably with recent advances in chemotherapy. ${ }^{1}$ The presence of brain metastases, however, is generally accepted as unfavourable and we have found no reports of successful treatment. We report a case in which extensive chemotherapy combined with surgery and radiotherapy seems to have been effective.

\section{Case report}

A 25-year-old postgraduate student presented in December 1974 with a swollen right testis. Orchidectomy and histological examination showed a malignant teratoma with trophoblastic features. Lymphangiography showed metastases in iliac nodes. He was treated by pelvic and para-aortic irradiation to a dose of 4000 rads. He remained well until January 1976 . He then developed a right lower-lobe pneumonia as well as severe frontal headaches followed by a mild left hemiparesis. Chest $x$-ray examination confirmed the presence of metastatic tumour in the right lower lobe and also in the left mid-zone. Computerised tomography (CAT) of the brain showed deposits in the right parietal and right frontal regions. His serum gonadotrophin (HCG) concentration was $52000 \mathrm{IU} / 1$. Alpha fetoprotein (AFP) was indetectable. Lymphangiography showed no evidence of intra-abdominal metastases.

Treatment was started in January 1976. Over the next 12 months he received 19 courses of systemic chemotherapy, usually in conjunction with intrathecal methotrexate (figure). By January 1977 there had been a partial response, as judged by: (1) resolution of the hemiparesis after two months; (2) sequential CAT brain scans showing improvement but also a persistent abnormality in the right parietal area; (3) sequential chest radiographs showing partial resolution but isolated shadows in the right and left midzones; (4) serial serum HCG concentrations, initially falling to normal after 10 weeks' treatment but later rising, indicating persistent active tumour (figure). Consecutive right and left thoracotomies to remove residual lung metastases were performed in February and March 1977 (Mr A R Makey). A lesion from the right middle lobe contained only necrotic tissue 